\section{Primary orbital melanoma in an anophthalmic socket}

\section{Dear Editor,}

A 59-year-old male patient who had undergone enucleation of the right eye and ocular prosthesis placement 12 years prior, because of complications of alcohol injection for painful intraorbital neuropathy, sought treatment for a three-month history of a mass growing within the right orbit, which had resulted in extrusion of the prosthesis. A contrast-enhanced computed tomography (CT) scan showed a predominantly hyperdense, solid expansile lesion, with intense heterogeneous contrast enhancement, in the right intraconal and extraconal compartments (Figure 1). The lesion was in close contact with the right-side lateral/inferior rectus muscles, optic nerve, and lacrimal gland, as well as with the ocular prosthesis. Magnetic resonance imaging (MRI) of the orbits revealed a highly vascularized lobulated mass, with ill-defined margins, in the lateral compartment of the right orbit, primarily in the extraconal space, having no cleavage plane with the lateral rectus muscle, lacrimal gland, or ocular prosthesis. Within the lesion were deposits of material with a hyperintense signal on T1-weighted images and a markedly hypointense signal on T2-weighted images, possibly indicative of melanin deposits (Figure 2). Accordingly, the main diagnostic hypothesis was melanoma. For staging, we performed CT scans of the chest and abdomen, which identified no suspicious lesions.
A biopsy was performed, and examination of the biopsy specimen resulted in a diagnosis of extensively invasive, heavily pigmented, spindle cell melanoma of the orbit.

Primary intraocular melanomas are the most common malignant intraocular neoplasms in adults ${ }^{(1)}$. However, primary orbital melanomas are rare, accounting for $<1 \%$ of primary orbital tumors $^{(2)}$. Their incidence is higher in adults, and they typically manifest as painless proptosis. Primary orbital melanoma is histopathologically similar to uveal melanoma. To make the definitive diagnosis, it is necessary to demonstrate, by means of imaging examinations, that the lesion did not originate in the globe and does not represent metastasis from a distant site $^{(3)}$.

It is likely that primary orbital melanomas originate from embryonic remains of neural crest cells, which can be found along the ciliary nerves, scleral emissary channels, and optic nerve leptomeninges ${ }^{(3)}$. There have also been reports of orbital melanoma developing from residual melanocytes in anophthalmic sockets, up to 63 years after evisceration ${ }^{(4)}$.

In patients with orbital melanoma, contrast-enhanced CT is not specific for the diagnosis, showing a hyperattenuating mass with enhancement ${ }^{(5)}$. The specificity of MRI is greater than is that of CT, because melanin shows high signal intensity in T1weighted sequences and low signal intensity in T2-weighted sequences. In addition, studies show that the degree of melanin pigmentation correlates directly with the signal intensity in
Figure 1. Axial CT slices of the orbits before and after injection of contrast medium (A and $\mathbf{B}$, respectively) showing an expansile lesion, with heterogeneous enhancement, in the lateral compartment of the right orbit, with intraconal and extraconal components, in close contact with the right-side lateral/inferior rectus muscles, optic nerve, ocular prosthesis and lacrimal gland.

Figure 2. Axial MRI of the orbits, in T1-weighted and STIR sequences (A and $\mathbf{B}$, respectively) showing a lobulated, heterogeneous lesion in the intraconal and extraconal lateral compartments of the right orbit, with foci of high signal intensity in T1-weighted sequences. (black arrow) and low signal intensity in T2-weighted sequences (white arrow), with no signal drop in fat-suppressed sequences (images not shown), consistent with melanin deposits.
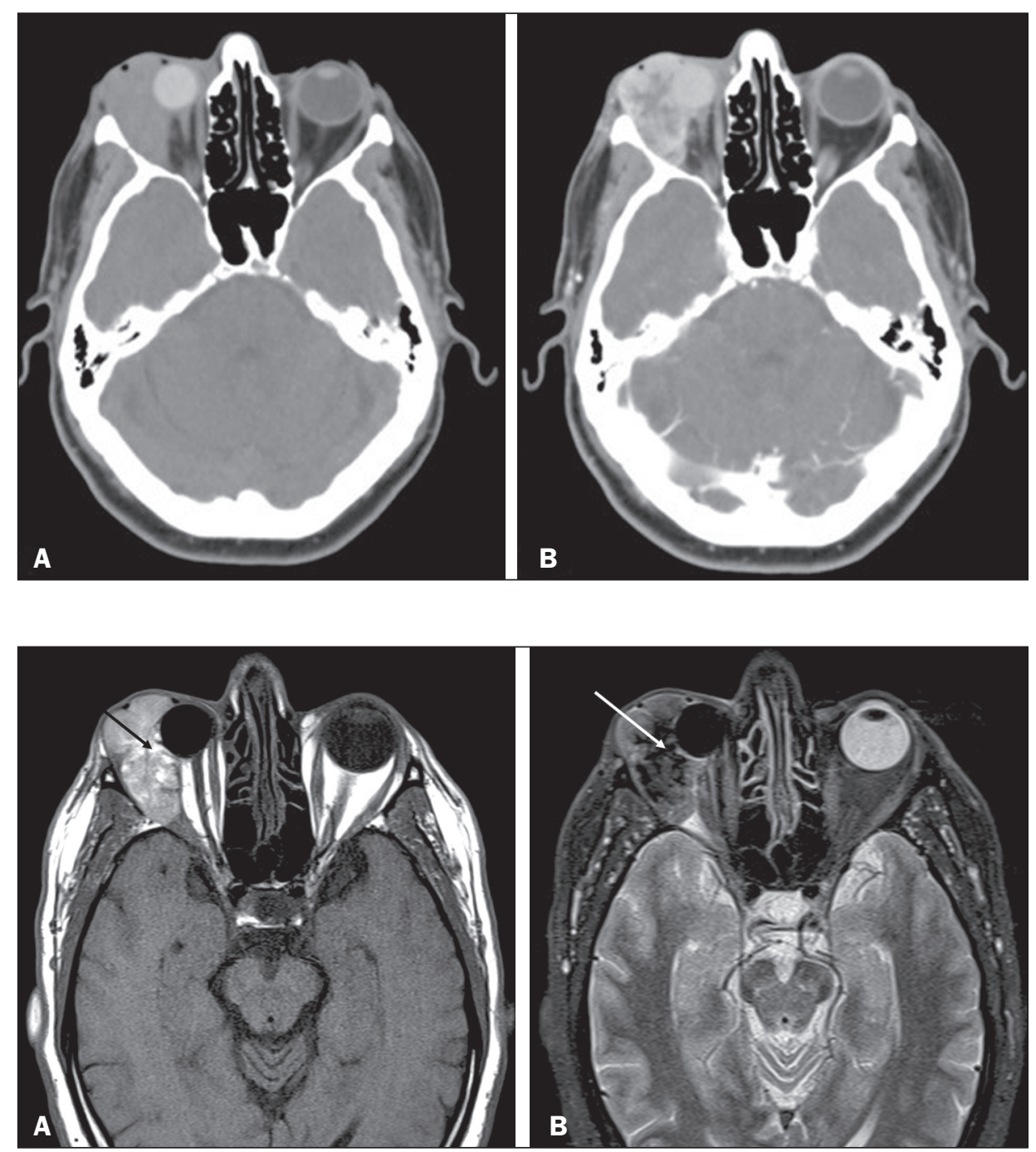
T1-weighted sequences. This finding is important to predict the prognosis, because intense pigmentation is related to a less favorable prognosis ${ }^{(5,6)}$. It is noteworthy that about $20 \%$ of melanomas are amelanotic ${ }^{(7)}$, therefore not presenting the characteristics mentioned above, which makes it difficult to differentiate them from other orbital lesions, such as metastases.

Despite its rarity, primary orbital melanoma is easily suspected because of the intrinsic behavioral characteristics of melanin in MRI sequences. Therefore, it should always be considered, even in cases affecting an anophthalmic socket.

\section{REFERENCES}

1. Spagnolo F, Caltabiano G, Queirolo P. Uveal melanoma. Cancer Treat Rev. 2012;38:549-53.

2. Elibol O, Yüksel N, Egilmez HR, et al. A case of primary orbital melanoma treated by local excision. Br J Ophthalmol. 1995;79:1 146-8.

3. Tellada M, Specht CS, McLean IW, et al. Primary orbital melanomas. Ophthalmology. 1996;103:929-32.

4. Akaishi PMS, Kitagawa VM, Chahud F, et al. Melanoma em cavidade anoftálmica secundária a evisceração - relato de 2 casos e revisão da literatura. Arq Bras Oftalmol. 2004;67:969-72.

5. Smoker WR, Gentry LR, Yee NK, et al. Vascular lesions of the orbit: more than meets the eye. Radiographics. 2008;28:185-204.

6. Mafee MF. Uveal melanoma, choroidal hemangioma, and simulating lesions. Role of MR imaging. Radiol Clin North Am. 1998;36:1083-99.

7. Lemke AJ, Hosten N, Bornfeld N, et al. Uveal melanoma: correlation of histopathologic and radiologic findings by using thin-section MR imaging with a surface coil. Radiology. 1999;210:775-83.

\section{Arthur de Freitas Ferreira ${ }^{1, a}$, Luiz Gonzaga da Silveira Filho ${ }^{1, b}$, Eduarda Lemes Dias ${ }^{1, c}$}

1. Universidade Federal do Triângulo Mineiro (UFTM), Uberaba, MG, Brazil. Correspondence: Dr. Arthur de Freitas Ferreira. Universidade Federal do Triângulo Mineiro. Avenida Getúlio Guaritá, 330, Nossa Senhora da Abadia. Uberaba, MG, Brazil, 38025-440. Email: arthurfreitasferreira@yahoo.com.br.

a. https://orcid.org/0000-0001-6722-2458; b. https://orcid.org/0000-0002-2541-5400; c. https://orcid.org/0000-0002-0213-1165.

Received 11 October 2017. Accepted after revision 22 December 2017.

http://dx.doi.org/10.1590/0100-3984.2017.0183

\section{$( \mathrm { cc } ) \longdiv { \mathrm { BY } }$}

\section{Prevalence of additional primary malignancies detected incidentally on PET/CT}

Dear Editor,

We entirely agree with the conclusions of Tibana et al. ${ }^{(1)}$. Although false-positives can occur with ${ }^{18} \mathrm{~F}$-fluorodeoxyglucose positron emission tomography/computed tomography (PET/ $\mathrm{CT}$ ), the prevalence of true-positives cannot be underestimated. Additional primary malignancies may often be identified by this means and the likelihood of cure is much increased if such malignancies are treated promptly and aggressively. It was unclear what is the actual prevalence of malignancies discovered with $\mathrm{PET} / \mathrm{CT}$ in this study.

The prevalence of additional malignancies discovered with PET/CT was highlighted in the various systems for breast ${ }^{(2)}$, bowel $^{(3)}$, prostate $\mathrm{e}^{(4)}$ and thyroid ${ }^{(5)}$ lesions. For example, in a study of 1665 patients, 70 incidentally detected lesions in the colon were identified and eventually 10 were diagnosed with bowel carcinoma ${ }^{(3)}$. There were additional pre-malignant lesions identified and early treatment was warranted in this scenario. Thus, it was found the prevalence of malignant and premalignant findings in the PET population was about $1.3 \%$. A similar series showed a lower number of carcinomas but more adenomas (which would, of course, be considered pre-malignant) in a slightly larger series ${ }^{(6)}$. Hence, the prevalence was similar (at $1.1 \%$ ). Knowing the prevalence may give a better idea of the importance of the incidental findings. This would be very helpful for both managing the individual patient as well as for public health and population health purposes.

\section{REFERENCES}

1. Tibana TK, Santos RFT, Arão Filho A, et al. Detection of additional primary malignancies: the role of CT and PET/CT combined with multiple percutaneous biopsy. Radiol Bras. 2019;52:166-71.

2. Bertagna F, Evangelista L, Piccardo A, et al. Multicentric study on ${ }^{18}$ F-FDG-PET/CT breast incidental uptake in patients studied for nonbreast malignant purposes. Rev Esp Med Nucl Imagen Mol. 2015;34: 24-9.

3. Lee JC, Hartnett GF, Hughes BG, et al. The segmental distribution and clinical significance of colorectal fluorodeoxyglucose uptake incidentally detected on PET-CT. Nucl Med Commun. 2009;30:333-7.

4. Yang Z, Hu S, Cheng J, et al. Prevalence and risk of cancer of incidental uptake in prostate identified by fluorine-18 fluorodeoxyglucose positron emission tomography/computed tomography. Clin Imaging. 2014;38: 470-4.

5. Adas M, Adas G, Koc B, et al. Incidental thyroid lesions on FDG-PET/CT: a prevalence study and proposition of management. Minerva Endocrinol. 2015;40:169-75.

6. Kamel EM, Thumshirn M, Truninger K, et al. Significance of incidental 18F-FDG accumulations in the gastrointestinal tract in PET/CT: correlation with endoscopic and histopathologic results. J Nucl Med. 2004;5:1804-10.

\footnotetext{
Joseph C. Lee $e^{1,2, a}$, Marcelo Santos Teles ${ }^{1, b}$

1. Department of Medical Imaging, The Prince Charles Hospital, Chermside, Queensland, 4032 Australia. 2. Faculty of Medicine, University of Queensland, Herston Rd, Herston, Queensland, 4006 Australia.

Correspondence: Joseph C. Lee. Department of Medical Imaging, The Prince Charles Hospital, Chermside, Queensland, 4032 Australia. Email: Joseph.Lee@ health.qld.gov.au.

https://orcid.org/0000-0002-7683-8825; b. https://orcid.org/0000-0002-2003-7279.

Received 25 July 2019. Accepted after revision 1 August 2019.
}

http://dx.doi.org/10.1590/0100-3984.2019.0097 